\title{
Burden of disease in South Africa: Protracted transitions driven by social pathologies
}

\author{
D Bradshaw, ${ }^{1,2}$ MSc, DPhil; N Nannan, ${ }^{1}$ MSc, PhD; V Pillay-van Wyk, ${ }^{1} \mathrm{PhD}$; R Laubscher, ${ }^{3}$ BComm (Maths); \\ P Groenewald, ${ }^{1} \mathrm{MB} \mathrm{ChB}, \mathrm{MPH}$; R E Dorrington, ${ }^{4}$ BCom, BSc Hons, BA, MPhil, FASSA \\ ${ }^{1}$ Burden of Disease Research Unit, South African Medical Research Council, Cape Town, South Africa \\ ${ }^{2}$ School of Public Health and Family Medicine, Faculty of Health Sciences, University of Cape Town, South Africa \\ ${ }^{3}$ Biostatistics Unit, South African Medical Research Council, Cape Town, South Africa \\ ${ }^{4}$ Centre for Actuarial Research, Faculty of Commerce, University of Cape Town, South Africa
}

Corresponding author: D Bradshaw (debbie.bradshaw@mrc.ac.za)

For several decades, researchers from the South African Medical Research Council have made invaluable contributions towards improving the health of the population through the analysis and interpretation of cause of death data. This article reflects the mortality trends in preand post-apartheid South Africa (SA), and describes efforts to improve vital statistics, innovations to fill data gaps, and studies to estimate the burden of disease after adjusting for data deficiencies. The profound impact of HIV/AIDS, particularly among black African children and young adults, is striking, within a protracted epidemiological transition and the current reversals of multiple epidemics. Over the next 20 years, it will be important to sustain and enhance the country's capacity to collect, analyse and utilise cause of death data. SA needs to support development in the region, harnessing new data platforms and approaches such as including verbal autopsy tools in the official system and improving data linkage.

S Afr Med J 2019;109(11 Suppl 1):69-76. https://doi.org/10.7196/SAMJ.2019.v109i11b.14273

During the latter half of the 20th century, the world's population experienced global improvements in mortality, resulting in a 20 -year increase in global life expectancy from an average of 47 years in $1950-1955$ to 69 years in $2005-2010{ }^{[1]}$ Omran $^{[2]}$ describes the epidemiological transition of disease that accompanies the change as the social, economic and demographic structures of society change, starting with a preponderance of infectious diseases and conditions related to malnutrition and childbirth, followed by an era when chronic and degenerative diseases are prominent. This pattern is characterised by initial declines in rates of death due to communicable diseases in the early stages of the transition, followed by increases and subsequent reductions in mortality attributable to non-communicable diseases (NCDs) in the advanced stages of the transition. However, based on the experience of middle-income countries, Frenk et al. ${ }^{[3]}$ outline a protracted bipolar transition with the coexistence of both types of conditions for extended time periods resulting from the social stratification of society.

South Africa (SA) is classified as an upper-middle-income country, yet high proportions of the population are unemployed and levels of poverty remain high. Furthermore, development trends are erratic and not steady. Examination of the trend in absolute poverty in SA in recent years, shows that although between 2006 and 2011 the country was making progress with reducing poverty, since 2011, this trend reversed. ${ }^{[4]}$

Social factors and inequalities play a pervasive role in the disease patterns experienced by the population. SA is a complex, multicultural society. Coovadia et al..$^{[5]}$ have described how racial and gender discrimination, the migrant labour system, the destruction of family life, vast income inequalities and extreme violence have affected health and health services in the country. In 1949, Sidney Kark, ${ }^{[6]}$ investigating the ongoing spread of syphilis among black African men, coined the term 'social pathologies' in demonstrating how the pattern of migrant labour developed to serve the mining industry resulted in the ongoing spread of sexually transmitted disease. He argued that the system of migratory labour had led to instability and pathology in family relationships and concluded that no treatment would stop the spread of syphilis in SA without addressing the economic factors involved. Myer et al. ${ }^{[7]}$ commented on how these social conditions of the region, and population mobility in particular, contributed to the structural conditions that fuelled the spread of HIV/AIDS some 40 years later.

For several decades, the South African Medical Research Council (SAMRC) has contributed to unpacking the trends in the burden of disease in the country and disparities in health. This started with analyses of the cause of death data in the 1970s, including a description of the extreme racial inequalities in health and highlighting of the inadequacies of the country's vital statistics. Under apartheid, the population was divided into the four racial categories defined by the Population Registration Act of 1950 (for white, coloured (mixed ancestry including Khoe, San, Malay, Europeans, Indonesians, Indians and Africans) and native (sic)) and the subsequent classification of Indians as non-aliens. Despite the repeal of the Population Registration Act No. 30 of 1950 in 1990 and the ending of apartheid in 1994, racial categories remain a feature in the class structure of today's society and the positive discrimination efforts of redress. In this article, we use the population group terminology of Statistics South Africa (Stats SA): black African, white, coloured, and Indian/Asian, which are generally based on selfreporting and self-identification. Since the 1990s, the SAMRC has been involved in initiatives to grapple with the data gap, including setting up demographic and surveillance sites and contributing to country efforts to improve the national health information system. The Burden of Disease Research Unit has undertaken National Burden of Disease studies that aim to address the data deficiencies and derive coherent estimates. 
To mark the occasion of the 50th anniversary of the SAMRC, this article reflects on the availability of burden of disease information in pre- and post-apartheid SA. It describes efforts to improve civil registration and vital statistics, and efforts to derive best estimates of the burden in the post-apartheid era, and presents information about trends and population group inequalities in health.

\section{Civil registration and vital statistics in SA}

Civil registration and the resulting vital statistics (CRVS) are recognised as essential public goods that benefit individuals and societies. ${ }^{[8]}$ Birth and death registration facilitates the realisation of several human rights in terms of proof of identity and citizenship, as well as providing a foundation for health statistics. The medical information on the cause of death provided by doctors at the time of death offers valuable insights into the health of the nation. SA has a well-established CRVS system, built over many years since its inception in 1926. ${ }^{[9]}$ However, for much of this period, it was only partial for the majority black African population. Attempts to investigate the cause of death pattern for black Africans resulted in a call for a review of the system in $1985 .{ }^{[10]}$ But the improvement of the whole health information system, including vital statistics, was only prioritised in the post-apartheid era, marked by the establishment of the National Health Information System South Africa in 1994. ${ }^{[11]}$ These initiatives made extensive use of the SAMRC 1995 investigation into vital registration and statistics in the Cape Town metropole, ${ }^{[12]}$ which had identified practical recommendations such as the need to amend the death notification form. In 1999, Bah ${ }^{[13]}$ highlighted the effect of the political history of SA on the coverage of the vital statistics system and described the construction of a more comprehensive system through the consolidation of all the geographical areas and the complexities of making the system comprehensive. The National Department of Health $(\mathrm{NDoH})$ led an initiative to standardise the cause of death information collected and ensure that necessary health information would be collected, resulting in the introduction of a new death notification form ${ }^{[14]}$ including the early introduction of tobacco-related questions. ${ }^{[15]}$ Interdepartmental efforts to improve registration included activities such as establishing provincial task teams and training officials. Since 1994, there has been great improvement in death registration ${ }^{[16]}$ and birth registration. ${ }^{[17,18]}$ However, the quality of medical certification and the lack of a field for the manner of injury ${ }^{[19]}$ on the death notification form are key reasons why the vital statistics system is not yet providing the highquality cause of death information required. ${ }^{[20,21]}$ Furthermore, the prevention of the health department from accessing cause of death information from the registration system means that this information cannot be used to conduct necessary public health surveillance. ${ }^{[22]}$

Bourne ${ }^{[9]}$ detailed the availability of SA mortality data from 1920 to 1992 , revealing their apartheid structure. He also highlighted the systematic coding of the cause of death information to various revisions of the International Classification of Diseases (ICD) and provided a bibliography of the available publications. ${ }^{\left[{ }^{[0]}\right.}$ These statistical reports provided multiple tabulations with a limited narrative, little interpretation and almost no evaluation. From 1968 onwards two statistical reports were produced: one for whites, coloureds and Asians and the other for black Africans living in selected magisterial districts of the Republic of South Africa. With the repeal of the Population Registration Act in 1992, population group was no longer collected on the death notification form. However, by 1998, population group was reintroduced on the death notification form to enable gains made in redressing health and other inequalities created by apartheid to be monitored. This reintroduction was contentious, owing to the challenges of definition and categorisation, the possibility of perpetuating racial stereotypes and the possibility of not adequately identifying and monitoring other social determinants of health, among other factors. Because of these and other concerns, population group is unknown for a significant proportion of the cause of death data. In $2000,25 \%$ of the cause of death data were missing information on population group, but this proportion fell significantly from around 2010 and was only $13 \%$ by 2016 .

The 7-year lag in the production of cause of death statistics, at a critical time when the HIV epidemic was taking hold in the country, placed cause of death statistics centre-stage of a politically charged debate resulting from AIDS denialism. In the absence of timely data on deaths in the country, the SAMRC developed a system to allow rapid monitoring of the changes in the age-sex pattern in the numbers of deaths by obtaining details of registered deaths directly from the National Population Register maintained by the Department of Home Affairs. In a landmark report on the trend in adult mortality in SA released in 2001, ${ }^{[23]}$ the SAMRC team demonstrated the rapidly emerging increase in adult mortality and deduced that AIDS had become the leading single cause of death by 2000. Using a model to anticipate deaths in future years, the authors estimated that if treatment was not made available, the numbers of deaths from AIDS would be expected to increase to account for more than double the number of deaths due to all other causes combined. They estimated that, in the absence of treatment, the epidemic could result in a total of $5-7$ million cumulative AIDS deaths in SA within the following 10 years.

This was not accepted by government at the time, even though Stats SA also published a report later that year, the Advance Release of Recorded Deaths, $1997-2000,{ }^{[24]}$ demonstrating the rapidly changing numbers of deaths with the same distinct age and sex pattern. However, the report was careful to not attribute the pattern to HIV/AIDS. This was followed, at the end of 2002, by the release of a report on a $12 \%$ sample of the cause of death for 1997 to $2001,{ }^{[25]}$ which reiterated the rapid change in mortality patterns. It identified the emergence of HIV, tuberculosis (TB), and influenza and pneumonia as main causes of death, but was unable to provide a reliable count of HIV/AIDS deaths owing to the high proportion of ill-defined causes, the extensive misattribution of AIDS deaths to the immediate cause such as pneumonia or TB, and difficulty in estimating the level of general under-registration of deaths.

From early 2003, Stats SA continued working on reducing the 7 -year backlog in the compilation of cause of death statistics, and in 2005 released the report for the period $1997-2003^{[26]}$ and resumed annual reporting thereafter. An automated procedure to determine the underlying cause of death was introduced as well as a strict coding procedure, removing any interpretive coding such as allocating 'retroviral disease' to HIV. More detailed reporting was introduced to make the data more usable.

After this, Stats SA has made anonymised unit record data, for each year of death from 1997 onwards, available through its online data archive. Previously, the Central Statistical Service had computerised the cause of death data from 1968 onwards, and the SAMRC consolidated these data through annual requests for electronic versions of the anonymised records. The SAMRC has standardised the core variable set, including a new geocode to the new nine provinces introduced in 1994. However, it remains important to interpret these data with caution, considering that not all deaths have been registered, and that the quality of medical certification is not optimal. ${ }^{[27]}$ 


\section{Closing data gaps and introducing innovations}

The SAMRC together with the University of Cape Town has continued to track the deaths recorded on the National Population Register. After correcting for the under-registration of deaths and births, the Rapid Mortality Surveillance (RMS) Report has been produced annually since $2011,{ }^{[28,29]}$ and the estimates have been used by the $\mathrm{NDoH}$ to monitor their performance against impact targets. The indicators include life expectancy at birth, the adult mortality index $\left({ }_{45} q_{15}\right)$, under-5 mortality rate, infant mortality rate and neonatal mortality rate, and in the most recent report, indicators that track mortality of older children and young adolescents aged 5 - 14 years $\left({ }_{10} q_{5}\right)$ as well as older adolescents and young adults aged 15 - 24 years $\left({ }_{10} q_{15}\right)$. In addition, the report includes an indicator of the maternal mortality ratio (MMR), which lags behind the other indices because it relies on the cause of death data reported by Stats SA. A similar methodology is used to calculate the premature mortality resulting from selected NCDs $\left(\mathrm{NCD}{ }_{40} q_{30}\right)$. Although ideally the indicators are best estimates of what is being measured, it is more important for tracking performance to ensure consistency of measurement over time. The prime example of this is the MMR, which for various reasons is difficult to measure accurately. The sensibleness of this approach is illustrated by a comparison of the RMS indicator with annually revised series of the MMR produced by the Institute for Health Metrics (IHME) and United Nations Maternal Mortality Estimation Inter-agency Group (MMEIG), demonstrating the great uncertainty in the estimates from the agencies above and below the RMS indicator. ${ }^{[30]}$

The poor quality of CRVS data in rural areas has led to the development of Health and Demographic Surveillance Systems (HDSS) sites, designed to track mortality trends and other health information of the population at selected sites. The Agincourt MRC/ Wits Rural Public Health and Health Transitions Research Unit set up a surveillance system in the rural north-east of the country in 1992, introducing the use of a verbal autopsy questionnaire to identify cause of death. ${ }^{[31]}$ A smaller site was then set up in the Dikgale area of Limpopo with financial support from the Norwegian Universities Committee for Development, Research and Education. ${ }^{[32]}$ The Africa Centre (now the Africa Health Research Initiative), an initiative involving the MRC and funded by the Wellcome Trust, established a surveillance system in rural KwaZulu-Natal Province in 2000. ${ }^{[33]}$ During a time when the national CRVS data could not provide reliable information about the mortality trends in rural settings, data from the Africa Centre provided extensive empirical evidence about the demographic and social impact of the HIV epidemic in severely affected populations. ${ }^{[3,34]}$ By 2000 the HIV/AIDS epidemic was advanced, resulting in increased mortality rates and significantly reduced life expectancy, with the period life table probability of a 15-year-old dying before the age of 60 years estimated at $58 \%$ for women and $75 \%$ for men. Although the observed mortality of $\sim 90000$ individuals over two decades in Agincourt documented significantly lower child mortality rates than the Africa Centre, ${ }^{[35]}$ the data highlighted that the HIV epidemic had hugely impacted on the cause of death profiles. ${ }^{[36]}$ The all-cause mortality doubled, and the increase in level was sustained for over 10 years. The HDSS sites have contributed to an international surveillance network, and in 2017, the SA government made an infrastructural investment supporting the South African Population Research Infrastructure Network (SAPRIN) to strengthen and harmonise the data from the three HDSS sites in the country and extend the health and demographic surveillance into urban areas. It is a long-term investment into a national research infrastructure funded by the National Department of Science and Innovation and hosted by the SAMRC, which is expected to provide a research platform for development-orientated research.

The lack of small-area deaths statistics led the SAMRC to collaborate with the CCT to enhance their system of compiling deaths statistics. The project developed a short list for coding the underlying cause, having observed that the specificity of the full ICD classification was beyond the level of detail available on the death notifications. ${ }^{[37]}$ In addition, the project focused on the presentation of the data, and the extreme health inequalities across the city were articulated for the first time. ${ }^{[38]}$ The project further demonstrated that mortality surveillance could identify the leading causes of premature mortality, provide useful data for monitoring the effectiveness of programmes and interventions, and reduce inequalities. ${ }^{[39]}$ In collaboration with the Western Cape Department of Health, the project introduced the IRIS-automated coding software, making it possible to provide routine ICD-10 cause of death coding across the province and contribute to efforts to reduce the burden of disease and inequalities through a league table of the causes of premature mortality. ${ }^{[40]}$ After the production of provincial mortality reports from 2008 onwards, ${ }^{[41]}$ the project had to be curtailed in 2014 through an amendment to the Births and Deaths Registration Act No. 51 of $1992^{[42]}$ that made the medical certificate of cause of death on the fourth page of the death notification form self-sealing to ensure confidentiality throughout the registration procedure. The stipulation that it may only be opened by an official of Stats SA has precluded identified individual-level information being made available for public health actions by the $\mathrm{NDoH}{ }^{[22]}$ Government's failure to allow the $\mathrm{NDoH}$ to have access to identified information from the civil registration system prevents numerous critical public health actions, resulting in the researchers calling for a revision of the death notification to enable Health access to identified information. ${ }^{[22]}$

\section{Trends in mortality - the emergence and reversal of multiple epidemics}

Recognising the data challenges, researchers from the SAMRC started analysing the official cause of death statistics in the late 1970s, identifying stark differences by population group. Wyndham and Fellingham ${ }^{[43]}$ undertook the first analysis of seasonality of mortality in SA, both confirming the broad patterns of higher deaths in winter months in the Indian/Asian and white populations and identifying a more complex pattern for black African and coloured populations, with summer highs in infants and winter peaks in older ages.

Wyndham and Irwig ${ }^{[4]}$ demonstrated the extremely high mortality experienced by coloured and black African children in 1970 . They further highlighted the enormous potential for improvement by pointing out the success that the CCT had achieved in reducing mortality of coloured children during the previous 30 years through provision of basic services for water and sanitation, preventive health services and primary healthcare through the day hospitals. They also pointed to the success of the Pholela pilot project in a rural area of KwaZulu-Natal, considered to be a founder example of primary healthcare, urging the government of the day to allocate a higher proportion of the health budget to programmes to reduce infant mortality.

In 1987, the SAMRC Institute for Biostatistics published a detailed report on the causes of death for 1984, using unit record data obtained from the Central Statistical Services. ${ }^{[45]}$ This report highlighted the under-registration of deaths of black Africans and the challenges with the classification of causes. Nonetheless, it described distinct racial mortality profiles: infectious disease and young ages for black Africans 
and coloureds, and cardiovascular conditions and other NCDs for whites. The very high burden from injuries in SA, accounting for $36 \%$ of the total loss of potential years of life (between 1 and 65 years), was also highlighted, with homicides being a major cause of death among black Africans and coloureds and motor vehicle accidents occurring in all groups. The report emphasised the importance of health promotion, improvement of socioeconomic conditions, nutrition, access to water and sanitation, and reducing over-crowding. It also identified the need to reduce the risk factors for chronic diseases and to improve access to healthcare, particularly primary care. The broader primary healthcare strategies of growth monitoring, oral rehydration, breastfeeding, immunisation, female education, family spacing and food supplements (GOBI-FFF strategy) were highlighted to improve child health.

Further analysis of death data from the mid-1980s showed that mortality levels were high in SA in comparison with other countries at the same level of development. ${ }^{[46]}$ These data also highlighted the considerable burden of NCDs, associated with modifiable risk factors. ${ }^{[47]}$ Using a simple approach, the considerable number of SA adults exposed to risk factors such as smoking and high blood pressure likely to lead to the development of chronic diseases was estimated, and a call was made for the allocation of resources to conduct research into prevention, diagnosis, management and rehabilitation of chronic diseases of lifestyle. ${ }^{[47]}$

Investigations of several causes of death have been undertaken over the years. However, with high proportions of so-called 'garbage' causes, including ill-defined signs and symptoms, misclassification of HIV/AIDS deaths, insufficient detail about the manner and external cause of non-natural deaths and the non-medical certification of deaths by rural headmen, it became essential to undertake burden of disease studies to determine coherent estimates of the levels and causes of mortality through the analysis and synthesis of several data sources. The Initial National Burden of Disease Study for $S A,{ }^{[48]}$ focused on the year 2000 , revealed a unique quadruple burden of disease for the country including HIV/AIDS and TB, NCDs, poverty-related conditions including maternal and child health problems, nutrition and other infections, and lastly, injuries. The second National Burden of Disease Study, ${ }^{[4]}$ spanning the period 1997 - 2012, highlighted the start of the reversal of several epidemics and demonstrated provincial and population group differentials in mortality.
To describe the trends in the burden of disease, we present historical estimates of mortality levels, together with a reanalysis of the cause of death data from the $1980 \mathrm{~s}^{[46,50,51]}$ and findings from the Rapid Mortality Surveillance ${ }^{[29]}$ and the second National Burden of Disease Study. ${ }^{[4]}$ Fig. 1 shows the trends in selected mortality indicators (with a dotted line indicating the difficulty in producing estimates during the 1990s) in early work. ${ }^{[46,50,51]}$ Subsequent work suggests that under-5 mortality probably bottomed out a bit higher than depicted by the early estimates. ${ }^{[22]}$ At some point in the early 1990s the slightly increasing life expectancy was reversed, and life expectancy by 2000 had fallen below the level in 1991 . Similarly, the under-5 mortality rate had been improving during the 1980s but started to increase around 1994. Based on census and survey data, Nannan et al. ${ }^{[51]}$ showed that SA had experienced a major drop in infant and child mortality between the 1970s and early 1990s, as seen in most other low- and middle-income countries, but little improvement in the neonatal mortality rate.

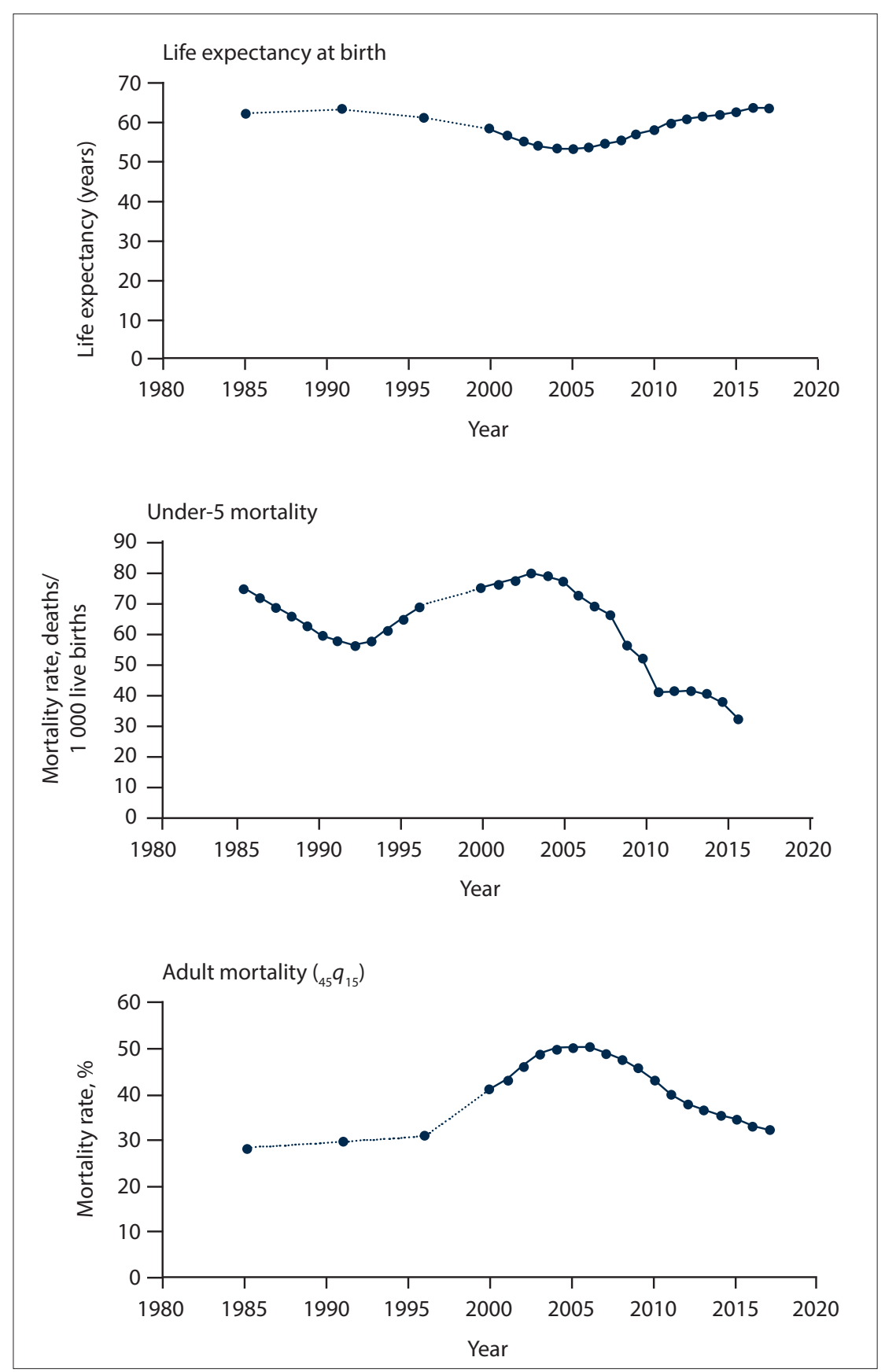

Fig. 1. Trends in life expectancy at birth, under-5 mortality and adult mortality $\left.{ }_{45} \mathrm{q}_{15}\right)$ in South Africa, 1985 - 2012 (adapted from Dorrington et al. ${ }^{[50]}$ (1999), Dorrington et al. ${ }^{[53]}$ (2004) and Dorrington et al. $\left.{ }^{[29]}(2017)\right)$. 
However, under-5 mortality started increasing in 1994 with the emergence of the generalised HIV/AIDS epidemic. The impact of HIV/AIDS is seen in the other indicators as well. Life expectancy fell to a low of 54 years in 2005, but has since increased to 64 years by 2017 . Adult mortality $\left({ }_{45} q_{15}\right)$ increased from $32 \%$ in 1985 to $50 \%$ in 2005, after which it declined to levels similar to 1985 by 2017 . The positive turnaround observed in all three of these indicators is in large part due to the extensive provision of antiretroviral therapy.

The trends in the level of mortality by population group are shown in Fig. 2 by age group based on the estimated probabilities of death per 1000 population. ${ }^{[29]}$ These trends highlight the persistent differentials in mortality, with rates for whites consistently the lowest and those for black Africans consistently the highest, with the exception of the oldest age group. Rates for Indians and coloureds in the oldest group are comparable to the black African rates. However, in the other age groups, the rates for coloureds are the second highest, followed by the rates for Indians. Mortality rates increased markedly for black Africans and to a lesser extent the coloured population in the post-apartheid period as the HIV/AIDS pandemic impacted.

Fig. 3 shows a comparison of disease categories from the early 1980s to 2012 by population group. The impact of HIV/AIDS together with TB is striking for black Africans and coloureds, while the proportion of deaths from other type 1 conditions including infectious diseases and maternal, perinatal and nutritional conditions decreased. Deaths from injuries decreased across all population groups over time. Throughout the transition from apartheid, SA experienced a high injury burden that was still persistent by the year 2000, with homicides being the most common cause followed by
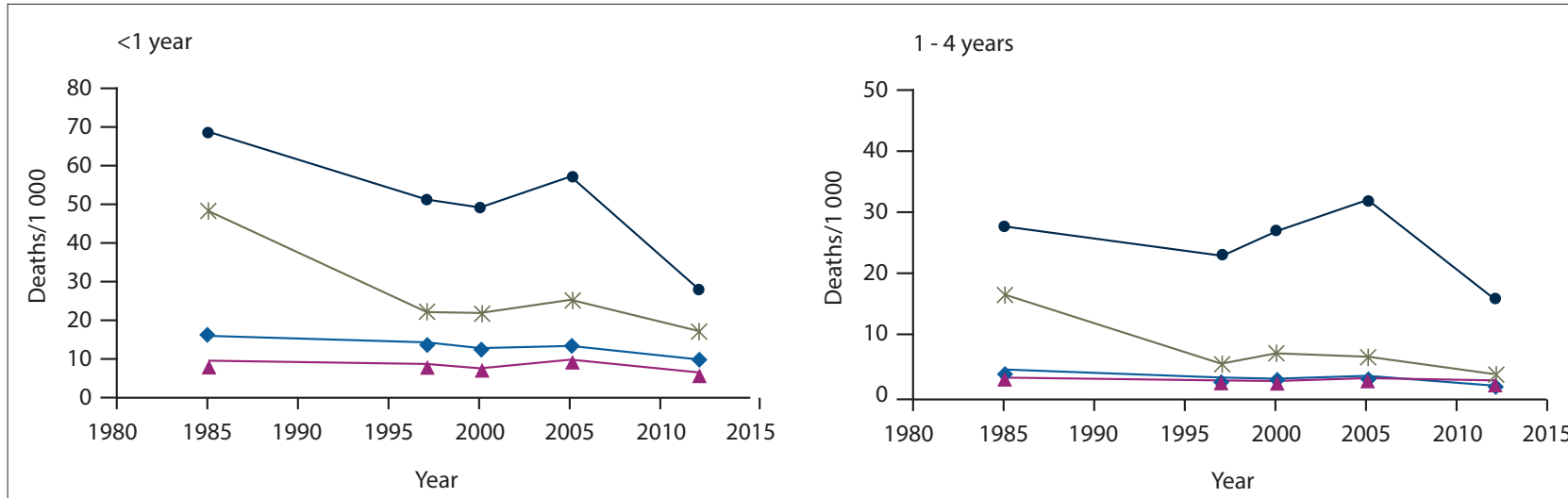

$5-14$ years

15 - 44 years
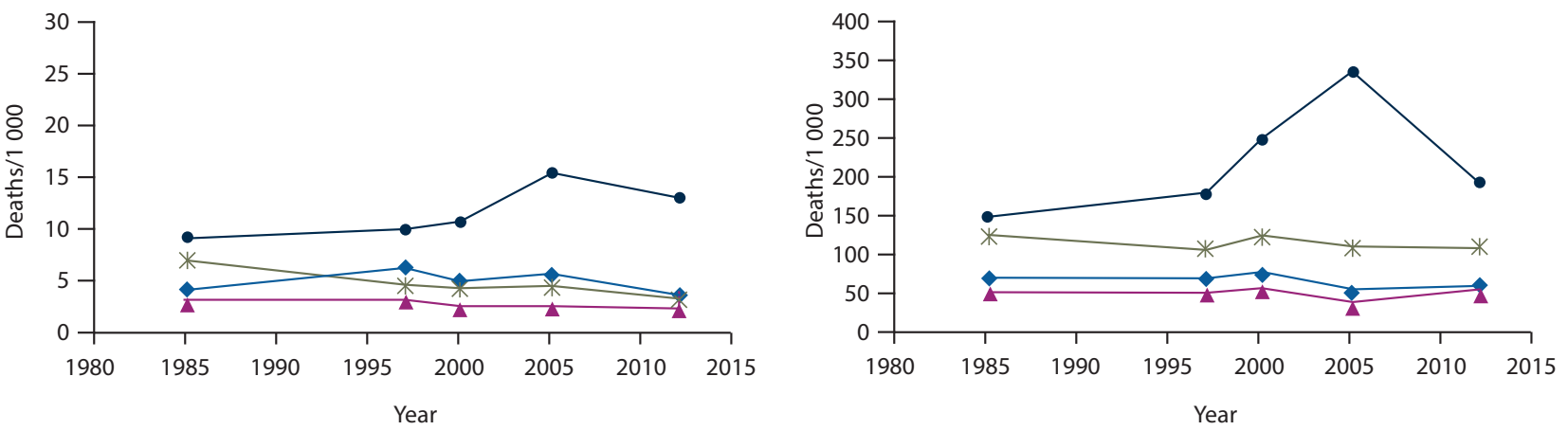

$45-64$ years

$65-84$ years
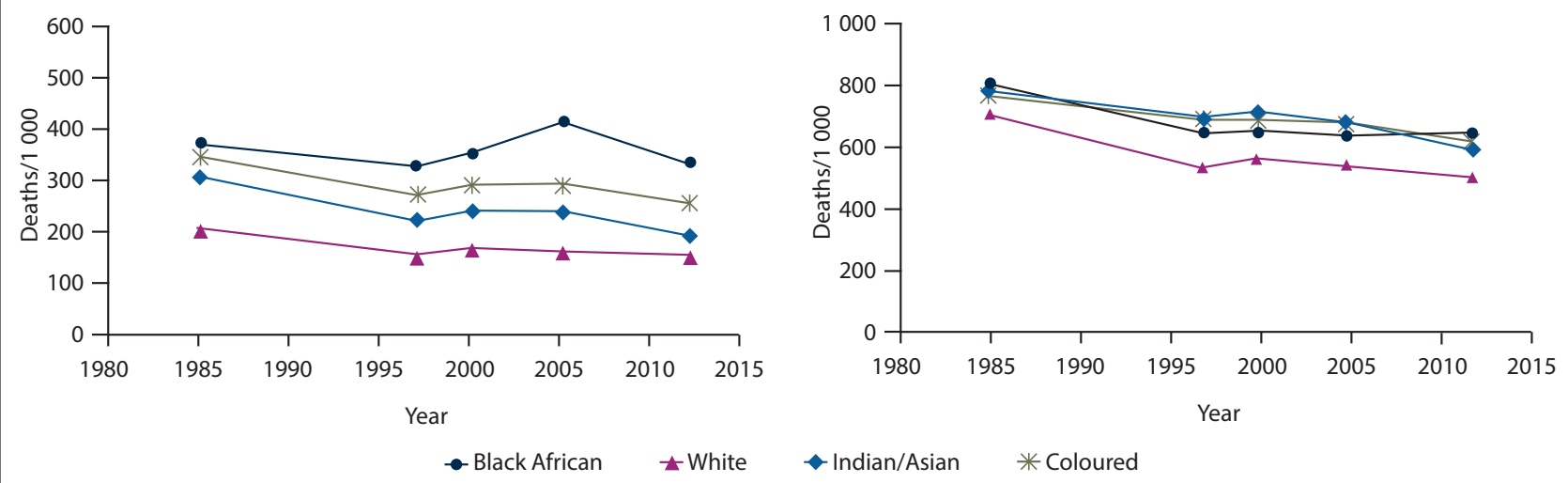

Fig. 2. Age-specific probability of death by population group per 1000 population, 1985 - 2012 (further analysis of Dorrington et al..$^{[50]}$ (1999) and Pillay-van Wyk et al. $\left.{ }^{[49]}(2017)\right)$. 


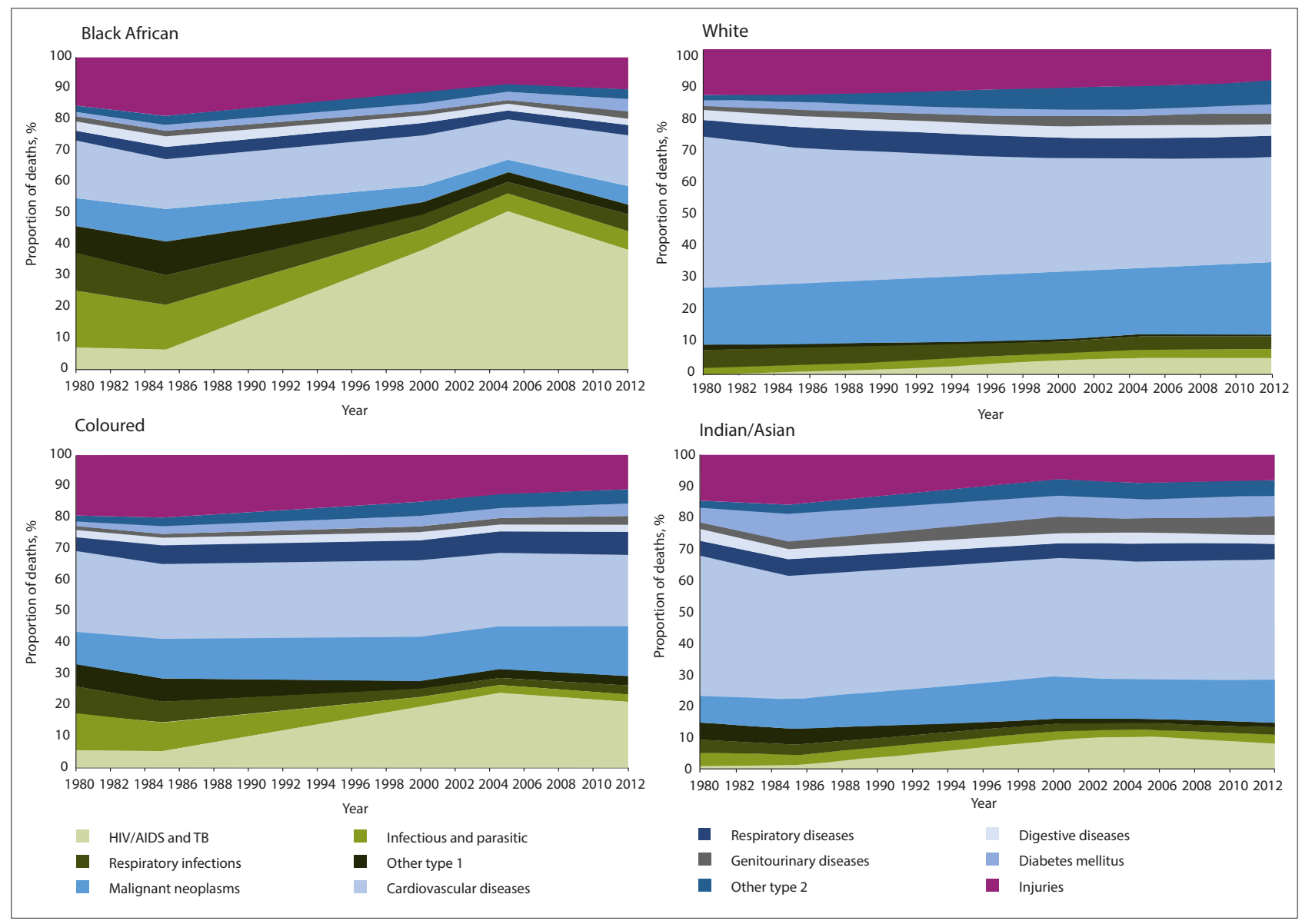

Fig. 3. Proportional distribution of disease categories over time by population group, 1985 - 2012 (authors' own analysis of data from Central Statistical Services and Pillay-van Wyk et al. $\left.{ }^{[49]}(2017)\right) .(T B=$ tuberculosis. $)$

transport injuries and then suicide. ${ }^{[54]}$ A national mortuary survey provided a clearer picture of the injury profile by population group in 2009. ${ }^{[5]}$ Transport deaths feature in all population groups, while homicide rates among black Africans and coloureds are very high. The rate of suicide among whites is almost double that among black Africans and coloureds.

From Fig. 3 it can be seen that NCDs accounted for high proportions of white and Indian/Asian deaths over the whole period, but the growth of NCD deaths among black Africans was arrested by the HIV/AIDS epidemic and the proportion has started to increase again since 2005. Deaths from cancers (malignant neoplasms) decreased among black Africans but increased in all the other population groups over time. This is a result of the decrease in deaths from oesophageal cancer and lung cancer. ${ }^{[56]}$ Indian/Asians and whites showed a high burden of deaths from cardiovascular diseases and cancers after 1985, while black Africans and coloureds carried the major burden of deaths from infectious and parasitic conditions. Furthermore, black African and coloured profiles show the challenge of the quadruple burden of disease, while Indian and white profiles are dominated by NCDs. Mayosi et al. ${ }^{[57]}$ highlighted the rising tide of NCDs associated with population growth and ageing, calling on government to ensure that primary care services integrate the care of chronic diseases and management of risk factors and to develop a national surveillance system.

Bradshaw et al. ${ }^{[58]}$ argued that a protracted bipolar transition was underway in SA in the 1990s, depicted by the combination of poverty-related diseases with NCDs. Given the high injury burden, it was concluded that there was a triple burden of disease.
However, the concept of a triple burden was short lived. Kahn et al. ${ }^{[59]}$ described the 'counter-transition' of increasing mortality among children and young adults due to acute diarrhoea and malnutrition, and as the HIV/AIDS epidemic took hold, Bradshaw et al. ${ }^{[48]}$ described the disease profile as a quadruple burden. More recently, Pillay-van Wyk et al. ${ }^{[49]}$ described the reversal of epidemics observed after 2010.

\section{Mortality data for action}

In addition to producing estimates and analysing the burden of disease at a national and provincial level, the cause of death profiles for health districts are generated after adjusting for ill-defined causes for the District Barometer published by the Health Systems Trust. ${ }^{[60]}$ The results are presented with a caveat concerning the data quality, and it is hoped that making the profiles available will highlight the utility of such information and fuel the process of improvement. Years of life lost as a measure of premature mortality are used to identify the conditions that need to be prioritised for prevention. This measure has been used in other studies, particularly in the form of league tables by geographical area. ${ }^{[38,41,48,49]}$ The second National Burden of Disease Study, for example, presented the leading causes of premature mortality for each province. While it was clear that all provinces need to prioritise AIDS awareness and HIV prevention programmes, the Western Cape and Gauteng need to involve other sectors in order to address the mortality of young people due to interpersonal violence. KwaZulu-Natal and North West need interventions aimed at reducing mortality due to cerebrovascular disease, including screening and managing high blood pressure. In an 
attempt to further present mortality data for action, Neethling et al ${ }^{[61]}$ developed an SA list of amenable conditions to highlight the extent of mortality resulting from failures in prevention and failures in treatment. It is anticipated that this list will be particularly useful for benchmarking health system performance.

Another approach to inform action to improve health is to assess the contribution of modifiable risk factors such as tobacco. ${ }^{[62]}$ The first comparative risk assessment study ${ }^{[33]}$ for SA quantified the contribution of 17 selected modifiable risk factors for the year 2000 and showed the dominance of unsafe sex as the key to preventing the burden of disease in the country. The study also highlighted the risk factors associated with poverty and underdevelopment, such as undernutrition, unsafe water, sanitation and hygiene and indoor smoke from solid fuels, as well as those associated with a Western lifestyle, such as alcohol, tobacco, diabetes, high blood pressure and high cholesterol. The high ranking of interpersonal violence as a risk factor is also likely to be associated with the extreme inequalities in SA society. In a study of poverty and NCDs, national survey data indicated that the risk factors for NCDs are prevalent among the poor, but that treatment and management of those on treatment are lacking. ${ }^{[64]}$

\section{Challenging estimates by international agencies}

For many developing countries, the only estimates of mortality and burden of disease that are available are produced by international agencies such as United Nations agencies (IGME, MMEIG and the Population Division) and the Gates Foundation-sponsored IHME. Left unchallenged, these become accepted as a true reflection of the countries' experience. While there have been some successes in influencing the estimates for SA that are made by international agencies, there remains a need for the global models to calibrate more closely with the local data ${ }^{[49,65]}$ and account for model uncertainty. ${ }^{[30]}$ As the quality of data reported by Stats SA improves, the differences should diminish. However, past estimates of mortality are likely to remain contested owing to the poor state of demographic information on most South Africans prior to the consolidation of the country in the post-apartheid period.

\section{Conclusions}

Mortality data form the foundation of health statistics. The SAMRC has made an invaluable contribution towards improving the health of the nation by strengthening mortality surveillance, unpacking the trends in mortality and making relevant information available for action. Analysis of mortality data in SA over the past 50 years has provided enormous insights into the health of the population and has identified the need for primary healthcare, health promotion, and intersectoral actions to improve health and reduce inequalities. The social determinants of health, particularly around injuries and the HIV/AIDS and TB epidemics, have been highlighted, as well as the health challenges associated with poverty.

As attention is drawn to the provision of personal health services by National Health Insurance, it is imperative to ensure that public health and health promotion functions, including surveillance, are adequately resourced. Calls to strengthen the country's public health capacity in health information and evidence, ${ }^{[6]}$ as well as to establish a Public Health Foundation to lead health promotion initiatives, ${ }^{[67]}$ have been made. Over the next 20 years, it will be important to continue building the country's capacity to collect, analyse and utilise cause of death data. The NDoH needs to collaborate with the Department of Home Affairs and Stats SA to continue strengthening CRVS and ensure that the data are used for public health actions. In addition, SA needs to continue efforts to support development in the region, harnessing new data platforms and approaches, for example, including verbal autopsy tools in the official system, improving data linkage and developing data visualisation applications to make the data more usable for action.

Acknowledgements. The SAMRC has provided ongoing support for the analysis and interpretation of cause of death data. This has enabled the Burden of Disease Research Unit to develop numerous collaborators and undertake a range of research.

Author contributions. All authors contributed to the concept, the consolidation of the data, the interpretation and the writing of the paper. RL set up the database for the historical cause of death data.

Funding. The SAMRC has supported the ongoing collation of the cause of death data and has supported the researchers to undertake the analyses. RED has been funded by the University of Cape Town.

Conflicts of interest. None.

1. United Nations. World Population Prospects 2019. New York: Department of Economic and Social Affairs, Population Division, 2019. https://population.un.org/wpp/ (accessed 30 June 2019).

2. Omran A. The epidemiological transition: A theory of the epidemiology of population change. Milbank Mem Fund Q 1971;49:509-538. Reprinted by the same journal as: Omran A. The epidemiological Mem Fund Q 1971;49:509-538. Reprinted by the same journal as: Omran A. The epidemiological
transition: A theory of the epidemiology of population change. Milbank Mem Fund Q 2005; 83(4):731transition: A theory of the epidemiology of population ch

3. Frenk J, Bobadilla JL, Sepuulveda J, Cervantes ML. Health transition in middle-income countries: New challenges for health care. Health Policy Plan 1989;4(1):29-39. https://doi.org/10.1093/heapol/4.1.29 4. Statistics South Africa. Poverty trends in South Africa: An examination of absolute poverty between 2006 and 2015. Report No 03-10-06. Pretoria: Stats SA, 2017. https://www.statssa.gov.za/publications Report-03-10-06/Report-03-10-062015.pdf (accessed 30 June 2019).

5. Coovadia H, Jewkes R, Barron P, Sanders D, McIntyre D. The health and health system of South Africa: Historical roots of current public health challenges. Lancet 2009;374(9692):817-834. https://doi. org/10.1016/S0140-6736(09)60951-X

6. Kark SL. The social pathology of syphilis in Africans. S Afr Med J 1949;23(5):77-84.

7. Myer L, Morroni C, Susser ES. Commentary: The social pathology of the HIV/AIDS pandemic. Int I

Epidemiol 2003;32(2):189-192. https://doi.org/10.1093/ije/dyg027

8. Setel PW, Macfarlane SB, Szreter S, et al. A scandal of invisibility: Making everyone count by co
everyone. Lancet 2007;370(9598):1569-1577. https://doi.org/10.1016/S0140-6736(07)61307-5

everyone. Lancet 2007;370(9598):1569-1577. https://doi.org/10.1016/S0140-6736(07)61307-5
Bourne DE. Sources of South African mortality data, 1910 - 1992. S Afr Med J 1995;85(10):1020-1022.

9. Bourne DE. Sources of South African mortality data, 1910 - 1992. S Afr Med J 1995;85(10):1020-10
10. Botha JL, Bradshaw D. African vital statistics - a black hole? S Afr Med J 1985;67(24):977-981.

11. Bradshaw D, Mbobo L. Informatics support. In: Harrison D, ed. South African Health Review. Durban: Health Systems Trust, 1995: chapter 9. https://www.hst.org.za/publications/South\%20African\%20 Health\%20Reviews/sahr95.pdf (accessed 30 June 2019).

12. Bradshaw D, Schneider M. Vital Registration and Statistics in South Africa: Case Study Metropolitan Cape Town. Cape Town: South African Medical Research Council, 1995.

13. Bah SM. The making and unmaking of a national but stratified vital statistics system in the Republic of South Africa and the new making of a more comprehensive vital statistics system. S Afr J Demogr 1999;7(1):45-50. https://www.commerce.uct.ac.za/Organisations/Demography/SA_Journal_ Demogr 1999;7(1):45-50. https://www.commerce.uct.ac.za/Organisations/Demography/SA_
of_Demography/SAJD/Volume\%207/SAJDem_1999_7_1_Bah.pdf (accessed 30 June 2019).

14. Bradshaw D, Kielkowski D, Sitas F. New birth and death registration forms - a foundation for the Bradshaw D, Kielkowski D, Sitas F. New birth and death registration
future, a challenge for health workers? S Afr Med J 1998;88(8):971-974.

15. Sitas F, Bradshaw D, Egger S, Jiang G, Peto R. Smoking counts: Experience of implementing questions on smoking on official death certification systems. Int J Epidemiol 2018;48(2):633-639. https://doi. org/10.1093/ije/dyy226

16. Joubert J, Rao C, Bradshaw D, Vos T, Lopez AD. Evaluating the quality of national mortality statistics from civil registration in South Africa, 1997 - 2007. Plos One 2013;8(5):e64592. https://doi org/10.1371/journal.pone. 0064592

7. Nannan N, Dorrington R, Bradshaw D. Estimating completeness of birth registration in South Africa 1996 - 2011. Bull World Health Organ 2019;97(7):468-476. https://doi.org/10.2471/BLT.18.222620.

18. Nhlapo M. An assessment of quality of birth registration in South Africa for fertility estimation. In: Odimegwu CO, Kekovole J, eds. Social Demography of South Africa: Advances and Emerging Issues.

19. Prinsloo M, Bradshaw D, Joubert J, Matzopoulos R, Groenewald P. South Africa’s vital statistics are currently not suitable for monitoring progress towards injury and violence Sustainable Development Goals. S Afr Med J 2017;107(6):470-471. https://doi.org/10.7196/SAMJ.2017.v107i6.12464.

20. Pillay-van Wyk V, Bradshaw D, Groenewald P, Laubscher R. Improving the quality of medical certification of cause of death: The time is now! S Afr Med J 2011;101(9):626.

21. Joubert J, Rao C, Bradshaw D, Dorrington RE, Vos T, Lopez AD. Characteristics, availability and uses of vital registration and other mortality data sources in post-democracy South Africa. Glob Health Action 2012;5(1):1-19. https://doi.org/10.3402/gha.v5i0.19263

22. Groenewald P, Azevedo V, Daniels J, et al. The importance of identified cause-of-death information being available for public health surveillance, actions and research. S Afr Med J 2015;105(7):528-530. https://doi.org/10.7196/SAMJnew.8019

23. Dorrington R, Bourne D, Bradshaw D, Laubscher R, Timaeus IM. The Impact of HIV/AIDS on Adult Mortality in South Africa. Technical Report. South Africa: Burden of Disease Unit, Medical Research Council, 2001. http://www.mrc.ac.za/bod/reports.htm (accessed 16 May 2019).

24. Statistics South Africa. Advanced release of recorded deaths, 1997 - 2000. Statistical release P0309.1. Pretoria: Stats SA, 2001. http://www.statssa.gov.za/publications/P03091/P030912000.pdf (accessed 30 June 2019).

25. Statistics South Africa. Causes of death in South Africa 1997 - 2001: Advance release of recorded causes of death. Statistical release P0309.3. Pretoria: Stats SA, 2002. http://www.statssa.gov.za/publications/ P03092/P030922001.pdf (accessed 30 June 2019).

26. Statistics South Africa. Mortality and causes of death in South Africa, 1997 - 2003: Findings from death notification. Statistical release P0309.3. Pretoria: Stats SA, 2005. https://www.statssa.gov.za/ publications/P03093/P03093.pdf (accessed 30 June 2019). 
27. Burger EH, Groenewald P, Rossouw A, Bradshaw D. Medical certification of death in South Africa moving forward. S Afr Med J 2015;105(1):27-30. https://doi.org/10.7196\%2FSAMJ.8578

28. Bradshaw D, Dorrington RE, Laubscher R. Rapid Mortality Surveillance Report 2011. Cape Town: South African Medical Research Council, 2012. http://www.mrc.ac.za/sites/default/files/ files/2017-05-26/RapidMortality2011.pdf (accessed 30 June 2019).

29. Dorrington RE, Bradshaw D, Laubscher R, Nannan N. Rapid Mortality Surveillance Report 2017. Cape Town: South African Medical Research Council, 2019. http://www.mrc.ac.za/sites/default/files/ files/2018-02-22/RapidMortalitySurveillanceReport2017.pdf (accessed 30 June 2019).

30. Dorrington RE, Bradshaw D. Acknowledging uncertainty about maternal mortality ratio estimates Bull World Health Organ 2015;94:155-156. https://doi.org/10.2471/BLT.15.155036

31. Tollman SM, Kahn K, Garenne M, Gear JS. Reversal in mortality trends: Evidence from the Agincourt field site, South Africa, 1992 - 1995. AIDS 1999;13:1091-1097.

32. Alberts M, Burger S, Tollman SM. The Dikgale Field Site. S Afr Med J 1999;89(8):851-852.

33. Hosegood V, Vanneste AM, Timæus IM. Levels and causes of adult mortality in rural South Africa: The impact of AIDS. AIDS 2004;18(4):663-671. https://doi.org/10.1097/00002030-200403050-00011

34. Tanser F, Hosegood V, Herbst K, et al. Cohort profile: Africa Centre Demographic Information System (ACDIS) and population-based HIV survey. Int J Epidemiol 2008;37(5):956-962. https://doi. org /10.1093\%2Fije $\% 2$ Fdym 211

35. Hargreaves JR, Collinson MA, Kahn K, Clark SI, Tollman SM. Childhood mortality among forme Mozambican refugees and their hosts in rural South Africa. Int J Epidemiol 2004:33(6):1271-1278 https://doi.org/10.1093/ije/dyh257

36. Kabudula CW, Tollman S, Mee P, et al. Two decades of mortality change in rural northeast South Africa. Glob Health Action 2014;7(1):25596. https://doi.org/10.3402/gha.v7.25596

37. Bradshaw D, Groenewald P, Bourne DE, et al. Making COD statistics useful for public health at local level in the city of Cape Town. Bull World Health Organ 2006;84(3):211-217. https://doi: 10.2471/ blt. 05.028589

38. Groenewald P, Bradshaw D, Nojilana B, et al. Cape Town Mortality 2001: Cause of Death and Premature Mortality in Cape Town - Key Findings. MRC Policy Brief. Cape Town: South African Medical Research Council, 2014. http://www.mrc.ac.za/sites/default/files/files/2017-05-26/ ctmortalitysummaryreport.pdf (accessed 30 June 2019).

39. Groenewald P, Bradshaw D, Daniels J, et al. Local-level mortality surveillance in resource-limited settings: A case study of Cape Town highlights disparities in health. Bull World Health Organ 2010;88(6):444-451. http://doi.org/10.2471/BLT.09.069435

40. Naledi T, Househam KC, Groenewald P, Bradshaw D, Myers JE. Improving data to reduce the burden of disease - lessons from the Western Cape. S Afr Med J 2009:99(9):641-642.

41. Groenewald P Evans J Morden E, et al. Western Cape Mortality Profile 2012. Cape Town: South African Medical Research Council, 2015. http://www.samrc.ac.za/sites/default/files/files/2017-05-26
Arition African Medical Research Council, 2015. http://www

42. Republic of South Africa. Births and Deaths Registration Act No. 51 of 1992. Regulations on the Registration of Births and Deaths, 2014. Government Gazette 26 February 2014;584(37373):5-74. http://www.gov.za/sites/www.gov.za/files/a51_1992.pdf (accessed 22 May 2015).

43. Wyndham CH, Fellingham SA. Climate and disease. S Afr Med J 1978;53(26):1051-1061.

44. Wyndham CH, Irwig LM. A comparison of the mortality rates of various population groups in the Republic of South Africa. S Afr Med J 1979;55(20):796-802.

45. Bradshaw D, Botha H, Joubert J, Pretorius JPG, van Wyk K, Yach D. Review of South African Mortality 1984. MRC Technical Report No. 1. Cape Town: Medical Research Council, 1987.

46. Bradshaw D, Dorrington RE, Sitas F. The level of mortality in South Africa in 1985 - what does it tell us about health? S Afr Med J 1992;82(4):237-240.

47. Steyn K, Fourie J, Bradshaw D. The impact of chronic diseases of lifestyle and their major risk factors on mortality in South Africa. S Afr Med J 1992:82(4):227-231.

48. Bradshaw D, Groenewald P, Laubscher R, et al. Initial burden of disease estimates for South Africa, 2000. S Afr Med J 2003;93(9):682-688.
49. Pillay-van Wyk V, Msemburi W, Laubscher R, et al. Mortality trends and differentials in South Africa from 1997 to 2012: Second National Burden of Disease Study. Lancet Glob Health 2016;4(9):e642-e653. Erratum in: Lancet Glob Health 2017;5(3):e275. http://doi.org/10.1016/S2214-109X(16)30113-9

50. Dorrington RE, Bradshaw D, Wegner T. Estimates of the Level and Shape of Mortality Rates in South Africa around 1985 and 1990 Derived By Applying Indirect Demographic Techniques to Reported Africa around 1985 and 1990 Derived By Applying Indirect Demographic Techniques to Reported Deaths. Cape Town: Medical Research Council,
files/2017-05-26/1999report.pdf (accessed 7 July 2019).

51. Nannan N, Timæus IM, Laubscher R, Bradshaw D. Levels and differentials in childhood mortality in South Africa, 1977 - 1998. J Biosoc Sci 2007;39(4):613-632. https://doi.org/10.1017/S0021932006001702 52. Johnson LF, Dorrington RE. Thembisa Version 4.2: A Model for Evaluating the Impact of HIV/AIDS in South Africa. Cape Town: University of Cape Town, 2019. http://www.thembisa.org/content/ downloadPage/Thembisa4_2report (accessed 30 June 2019).

53. Dorrington RE, Timæus IM, Moultrie TA, Nannan N. Estimates of provincial fertility and mortality in South Africa, 1985 - 1996. South Afr J Demogr 2004;9(2):25-57. https://www.commerce.uct. ac.za/Organisations/Demography/SA_Journal_of_Demography/SAJD/Volume\%209\%202/ SAJDem_2004_9_2_Dorrington.pdf (accessed 30 June 2019).

54. Norman R, Matzopoulos R, Groenewald P, Bradshaw D. The high burden of injuries in South Africa. Bull World Health Organ 2007;85(9):695-702. https://doi.org/10.2471/blt.06.037184

55. Matzopoulos R, Prinsloo M, Pillay-van Wyk V, et al. Injury-related mortality in South Africa: A retrospective descriptive study of postmortem investigations. Bull World Health Organ 2015:93(5):303313. http://doi.org/10.2471/BLT.14.145771

56. Nojilana B, Bradshaw D, Pillay-van Wyk V, et al. Emerging trends in non-communicable disease mortality in South Africa, 1997 - 2010. S Afr Med J 2016;106(5):58. http://doi.org/10.7196/SAMJ.2016. v106i5.10674

57. Mayosi BM, Flisher AJ, Lalloo UG, Sitas F, Tollman SM, Bradshaw D. The burden of noncommunicable diseases in South Africa. Lancet 2009;374(9693):934-947. http://doi.org/10.1016/ S0140-6736(09)61087-4

58. Bradshaw D, Schneider M, Dorrington R, Bourne DE, Laubscher R. South African cause-of-death profile in transition - 1996 and future trends. S Afr Med J 2002;92(8):618-623.

59. Kahn K, Garenne ML Collinson MA, Tollman SM. Mortality trends in a new South Africa: Hard to make a fresh start. Scand J Public Health 2007;35(69 Suppl):26-34. https://doi.org/10.1080/14034950701355668 60. Groenewald P, Bradshaw D, Day C, Laubscher R. Burden of disease. In: Massyn N, Peer N, English R, Padarath A, Barron P, Day C, eds. District Health Barometer 2015/16. Durban: Health Systems Trust, 2017. https://www.hst.org.za/publications/District\%20Health\%20Barometers/12\%20 (Section\%20A)\%20Burden\%20of\%20disease.pdf (accessed 30 June 2019).

61. Neethling I, Groenewald P, Schneider H, Bradshaw D. Trends and inequities in amenable mortality between 1997 and 2012 in South Africa. S Afr Med J 2019;109(8):597-604. https://doi.org/10.7196/ SAMJ.2019.v109i8.13796

62. Sitas F, Egger S, Bradshaw D, et al. Differences among the coloured, white, black, and other South African populations in smoking-attributed mortality at ages 35 - 74 years: A case-control study of 481,640 deaths. Lancet 2013;382(9893):685-693. http://doi.org/10.1016/S0140-6736(13)61610-4

63. Norman R, Bradshaw D, Schneider M, et al. South African Comparative Risk Assessment Collaborating Group. A comparative risk assessment for South Africa in 2000: Towards promoting health and preventing disease. S Afr Med J 2007;97(8 Pt 2):637-641

64. Schneider M, Bradshaw D, Steyn K, Norman R, Laubscher R. Poverty and non-communicable diseases in South Africa. Scand J Public Health 2009;37(2):176-186. http:///oi.org/10.1177/1403494808100272

65. Dorrington RE, Bradshaw D. GBD 2016 estimates problematic for South Africa. Lancet 6. Dorrington RE, Bradshaw D. GBD 2016 estimates problematic
2018;392(10149):735-736. http://doi.org/10.1016/S0140-6736(18)31987-1

66. Bradshaw D, Norman R, Lewin S, et al.; South African Comparative Risk Assessment Collaborating Group. Strengthening public health in South Africa: Building a stronger evidence base for improving the health of the nation.S Afr Med J 2007:97(8 Pt 2):643-649.

67. Perez AM, Ayo-Yusuf OA, Hofman K, et al. Establishing a health promotion and development foundation in South Africa. S Afr Med J 2013;103(3):147-149. http://doi.org/10.7196/SAMJ.628 